\title{
LETRAMENTO LITERÁRIO NA PANDEMIA
}

\section{ARTIGO DE REVISÃO}

SOUZA, Cynthia Almeida de ${ }^{1}$

SOUZA, Cynthia Almeida de. Letramento literário na Pandemia. Revista Científica Multidisciplinar Núcleo do Conhecimento. Ano 05, Ed. 12, Vol. 03, pp. 26-37. Dezembro de 2020. ISSN: 2448-0959, Link de acesso: https://www.nucleodoconhecimento.com.br/sem-categoria/literario-na-pandemia

\section{RESUMO}

Por conta da Pandemia, os estudantes tiveram a rotina alterada completamente. Como ampará-los nessa situação atípica? Este artigo propõe conhecer iniciativas escolares para favorecer o letramento literário no contexto de Pandemia. Para tanto, foi realizada uma pesquisa bibliográfica com base em teóricos como: Rildo Cosson, Roxane Rojo e Marisa Lajolo, Rubem Alves, entre outros, bem como um levantamento de Projetos que foram reconfigurados mediante o ensino remoto, no período de maio a agosto de 2020. Foram selecionados 04 projetos, cujas propostas foram descritas e analisadas. O resultado de tal análise evidenciou que, apesar da educação pressupor o toque, o corpo a corpo, deve-se encontrar meios de chegar aos alunos e reconhecer a tecnologia como uma aliada nesse processo.

Palavras-chave: letramento literário, educação, tecnologia, pandemia.

\section{INTRODUÇÃO}

Façamos da interrupção um caminho novo (Fernando Sabino)

\footnotetext{
${ }^{1}$ Especialização em Metodologia do Ensino de Língua Portuguesa e Estrangeira, pela Faculdade Internacional de Curitiba; Graduação em Letras/Língua Portuguesa, pela Universidade Federal do Pará.
} 
Criado por Graça Paulino, o termo letramento literário é definido por Cosson (2014) como o processo de apropriação da literatura enquanto linguagem, ou seja, não se trata de algo estático, mas sim contínuo e permanente. Pode-se iniciar o convívio com o universo literário desde a tenra infância ao se entoam cantigas de ninar. A partir daí, o que as pessoas ouvem, leem e/ou assistem, é internalizado e passam a aplicar essas experiências em situações da vida.

Rildo Cosson pontua que o letramento literário precisa da escola para se concretizar. Aliás, isso fica claro em autores como Magda Soares e Roxane Rojo, elas afirmam que a escola é uma agência de letramentos.

O presente artigo aborda o letramento literário, ressaltando alguns Projetos de escolas que precisaram adaptar-se à situação de ensino remoto provocado pelo novo Coronavírus (COVID-19), para que continuassem cumprindo a missão de motivar a leitura e práticas de letramento, dessa vez, em casa. Assim, no período de maio a agosto de 2020 foram selecionados 04 projetos que estão em consonância com os pressupostos teóricos que norteiam a pesquisa.

Todas as informações sobre os projetos foram obtidas por informação verbal em lives e entrevistas. Os três primeiros Projetos são iniciativas de professoras mestrandas, orientadas pela professora Flávia Aninger de Barros, da Universidade Estadual de Feira de Santana (Bahia), do Mestrado Profissional em Letras. As mestrandas, que iriam aplicar os Projetos como intervenção nas escolas, reconfiguraram as propostas para virtuais. O quarto projeto pertence à Escola Frei Elias Zulian, Ponta Grossa (PR), coordenado pela Professora Jacqueline Machado, destinado aos alunos do ensino fundamental, do $1^{\circ}$ ao $5^{\circ}$ ano; surgiu em 2016 e, com a paralisação das aulas presenciais, precisou ser repensado.

\section{PROJETO: A VEZ E A VOZ DA LITERATURA DE CORDEL}

Propomos favorecer a ampliação da competência leitora dos estudantes, utilizando 0 gênero literário Cordel como contribuição para o desenvolvimento do seu repertório cultural, através da promoção de práticas e eventos de letramento virtuais. Neste novo cenário as discussões no âmbito da Educação estão pautadas em palavras ou 
expressões como: ensino híbrido, novo normal, reinventar-se, adaptação, atividade remota, uma situação complexa, mesmo para aqueles já inseridos nesse novo formato de ensino-aprendizado. (Fala da Prof. ${ }^{\text {a }}$ Simônica Neves apud BARROS, 2020)

Por isso, a primeira ideia de intervenção nas escolas que seria a elaboração de uma sessão pedagógica, com atividades para provocar autonomia e curiosidade do estudante, modificou-se para a formatação atual:

- Criação de um ambiente virtual na Plataforma EAD, em módulos.

- Ênfase no espaço cordelitário.

Com esse novo formato, foi possível continuar o trabalho com o cordel, um bom exemplo de literatura que promove o letramento literário, pois

...a presença do poema de cordel, como estratégia para formar o leitor literário, representa uma forma artística do dizer e do ser no mundo mais próximo da realidade deles e sinaliza como um artefato pertinente diante do contexto de defasagem da competência leitora apresentada pelos alunos. (SANTOS, 2016, p.14)

Devido a essa característica do cordel, a professora Simônica Neves, afirma que o letramento literário pode ocorrer em qualquer lugar, inclusive em casa, desde que propicie a leitura. Assim, os objetivos redesenhados desse projeto compreendem:

- Socializar atividades multimodais para o desenvolvimento das práticas de leitura do educando;

- Viabilizar a ampliação do repertório cultural do educando, bem como contribuir para a sua formação de leitor crítico-reflexivo, através de cordéis;

- Promover a integração entre o educando e a leitura literária por meio da dinamicidade dos recursos tecnológicos;

- Criar um vínculo entre o educando e a leitura;

- A tecnologia a serviço da pedagogia.

Quanto à citada multimodalidade, Rojo (2013, p.7) alerta que "é preciso que a instituição escolar prepare a população para um funcionamento da sociedade cada vez mais digital e também para buscar no ciberespaço um lugar para se encontrar, de 
maneira crítica, com diferenças e identidades múltiplas”. Nesse sentido, o projeto reconhece a possibilidade dos textos multimodais, os quais integram várias linguagens (imagens, sons, movimento, cores...).

Quanto à proposta de leitura, esta se harmoniza com as palavras de Freire (1989, p. 13) em que "a leitura da palavra não é apenas precedida pela leitura do mundo, mas por uma certa forma de 'escrevê-lo' ou de 'reescrevê-lo', quer dizer, de transformá-lo através da nossa prática consciente." Assim, considera-se que

A leitura crítica é geradora de significados, em que ao ler, o leitor concorda ou discorda da ideia principal. Isto faz com que seja diferenciada da decodificação de sinais, reprodução mecânica de informações que por muito tempo foi considerada como interpretação textual. "[...] como atividade constitutiva de sujeitos capazes de interligar o mundo e nele atuar como cidadãos" (BRANDÃO; MICHELITTI, 1998, p. 22).

Equitativamente, Barros (informação verbal, 2020) conceitua letramento literário como "toda prática docente que se encaminha para uma prática de leitura mediada, consciente, para validação dos sentidos do texto, para que a leitura não seja mera decodificação e que a gente possa trabalhar para a formação de leitores". Este posicionamento da professora demonstra o esforço para a formação de leitores críticos, capazes de argumentar e serem cidadãos.

Nesse sentido, é importante destacar que letramento não é alfabetização. Segundo Rojo (2009), o letramento compreende ao processo de leitura e escrita fazendo relação às práticas sociais, enquanto a alfabetização é um tempo na vida escolar onde os alunos aprendem a ler e escrever. "O foco do letramento é fazer com que este aluno alfabetizado tenha capacidade de fazer um uso social desse domínio. É uma 'alfabetização dentro da alfabetização'. Letramento literário é uma das facetas do letramento" (RIBEIRO, 2012, p.02).

Não obstante, conforme Rojo (2009), como boa parte da população não participa de determinadas práticas letradas, cabe à escola compensar esse déficit e apresentar os alunos a diversos gêneros textuais produzidos em diferentes domínios discursivos, surgindo daí duas versões de letramento: uma fraca - voltada apenas para adaptar o 
indivíduo a uma sociedade cada vez mais complexa; e outra forte - voltada para os letramentos críticos e cidadãos.

Seguindo essa ótica, Simônica Neves (informação verbal) admite, com bastante razão, que "o livro não é algo do cotidiano dos nossos alunos, mas a gente pode encontrar formas de chegar até eles. Então penso que o cordel é um caminho para chegar a outras leituras." Esta afirmativa reforça a convicção de que o aprendizado possui muitos contornos, por isso o ensino é desafiador e o professor precisa estar preparado.

\section{PROJETO: BAÚ DE LEITURAS - CONTOS}

Propomos que, uma vez que as escolas estão fechadas, criar um ambiente virtual de aprendizagem, com a vantagem de ampliar para vários temas, com a particularidade que são educandos de orfanato. Os alunos da periferia precisam ter acesso ao poder de transformar (Fala da Prof. - Kátia Bispo Brandão Santos apud BARROS 2020).

Desta maneira, o projeto teve como finalidades:

- Integrar a tecnologia digital do desenvolvimento da competência leitora dos estudantes;

- Possibilitar a democratização da leitura;

- Propor atividades inferenciais na exploração dos livros lidos.

Todos esses objetivos aliados às particularidades dos educandos remetem à leitura como recurso reparador, e nesse contexto é oportuno citar Michèle Petit. A antropóloga argumenta, em entrevista ao jornal $O$ Globo que o trabalho de pessoas como os bibliotecários de Medellín nada tem de ingênuo:

Eles sabem que a literatura não vai reparar as violências ou as desigualdades do mundo, mas observam que ela oferece um apoio notável para colocar o pensamento em ação, para provocar o autoquestionamento, suscitar um desejo, uma busca por outra coisa...

As experiências de leitura compartilhada [...] podem facilitar a apropriação dos textos, desde que eles não sejam percebidos como algo imposto. 
... Junte-se a isso as dificuldades econômicas e a distância dos locais onde se podem encontrar suportes escritos. Nessas famílias, se as crianças ou adultos acabam lendo, e até vivendo a leitura com alegria, é graças a um encontro, ao acompanhamento caloroso de um mediador (professor, bibliotecário, amigo, assistente social...) que tem gosto por livros e sabe tornar esses objetos desejáveis, o que é uma arte.

A professora Kátia Bispo Brandão Santos assinala que, segundo Antônio Cândido, a literatura é um direito humano, é um bem indispensável à humanização, e garante (informação verbal):

nós não podemos negar esse direito aos nossos alunos, a literatura não pode ser apenas para um grupo específico, um grupo elitizado. Os alunos da escola pública, e no meu caso os alunos do subúrbio, da periferia, eles precisam ter acesso, eles já foram expropriados de tantas coisas, de tantos bens culturais... eles precisam ter acesso a esse novo mundo, podem mergulhar e conhecer novas realidades. A literatura tem poder de transformar, trazer novas perspectivas para o sujeito. Barthes diz que se todas as disciplinas precisassem ser extintas, que ficasse a literatura porque na literatura cabem todas as outras ciências.

Essa postura da professora Kátia coaduna com um dos maiores promotores da literatura atual, o crítico literário Tzvetan Todorov, que em sua obra "A literatura em perigo" defende a polissemia dos textos literários: "a maneira de se tratar as obras literárias está colocando-as em perigo, está mortificando a arte. Isso se dá pela visão errônea de que literatura é para poucos, quando na verdade é para todos" segundo o autor.

Devemos compreender que o letramento literário é uma prática social e, como tal, responsabilidade da escola. A questão a ser enfrentada não é se a escola deve ou não escolarizar a literatura, como bem nos alerta Magda Soares, mas sim como fazer essa escolarização sem descaracterizá-la, sem transformá-la em um simulacro de si mesma que mais nega do que confirma seu poder de humanização (COSSON, 2009, p.23)

Nessa perspectiva, a professora Kátia revela (informação verbal):

Por medida de proteção ao bem maior que é a vida, as aulas presenciais estão suspensas, mas como não podemos deixar de assegurar o direito ao acesso à literatura, adaptamos nosso Projeto. A leitura sobrevive 
através dos recursos digitais. É instrumento de empoderamento. Que nossos alunos tenham vez e voz na sociedade que estamos vivendo!

Nota-se que a referida questão da humanização é função da literatura, pois esta oferece ao sujeito além do prazer, o conhecimento e uma visão crítica dos acontecimentos em sua volta.

\section{PROJETO: VIAGEM ATRAVÉS DOS CURTAS - PARA UMA INTERPRETAÇÃO ALÉM DAS PALAVRAS}

Uma proposta de intervenção pedagógica que busca explorar os aspectos semióticos e multimodais de textos através das leituras fílmicas em uma Plataforma digital de aprendizagem.

Para aproximar as aulas de português à tecnologia e ao entretenimento. Uma forma de atraí-los com filme, pipoca... (Fala da Prof. ㄹ Eliene Ramos da Silva apud BARROS 2020).

Essa proposta teve como principais focos:

- Ampliação da capacidade de compreensão e interpretação de textos;

- Proporcionar experiência de letramento multimídia;

- Orientar sobre a utilização de recursos audiovisuais como ferramentas textuais;

- Aprimorar a competência linguística.

Diante disso, o ponto de partida foi a motivação, segundo a professora Eliene (informação verbal):

Escolhi os curtas-metragens porque trazem temáticas de interesse dos alunos... espaço para além dos curtas com outros gêneros, texto e reflexão, dialogando com o tema através de links, obras com a mesma temática (uma isca para outras leituras). Ante a Pandemia a educação se ressignificou, outros paradigmas nas abordagens dos conteúdos escolares são urgentes. Agora mais do que nunca, "novos desafios ao ensino de língua começam a agigantar-se".

Com efeito, a fala da professora está em sintonia com Cosson (2014, p. 55) quando fala na escolha das "iscas", conforme o autor a motivação está relacionada ao sistema de cognição de cada um "inclui os valores pessoais, e é influenciado pelo ambiente 
físico e social. O objetivo é estabelecer uma ligação com a obra que se vai ler, integrando na atividade a leitura, a escrita e a oralidade". Sobre a seleção de obras, "o letramento literário trabalhará sempre com o atual, seja ele contemporâneo ou não" (idem); ele entende por atual a obra que apresenta uma significação para o seu leitor, em seu tempo.

Assim, Cosson (2014, p 34.) destaca que o docente tem a obrigação de trabalhar a leitura das escolas literárias, pelo fato de a literatura ter a capacidade de mostrar através da ficção a representação da realidade social, com temas que se transcendem ao longo dos anos. O professor é o mediador, e através da sua metodologia, os discentes vão aprender a ter gosto pela leitura e perceber a importância dos textos literários.

Por isso, Barros (2020) salienta a importância da Leitura como sendo "retocar nosso modelo de mundo, uma educação em que a fala do aluno é acolhida, por que o aluno não lê? Depende de estratégias, de como conduzimos...". Nesse aspecto Lajolo (informação verbal, 2018) ensina que "O professor se aproxima do aluno quando ele lê as coisas que o aluno gosta ou que o professor pretendia levar para um determinado sentido o aluno leva em outro sentido completamente diferente." Com isso, as mencionadas professoras trazem uma enorme contribuição para a necessidade da motivação.

\section{PROJETO “LER PARA GOSTAR, GOSTAR PARA LER”}

Diferentemente dos projetos anteriores não se criou um ambiente virtual específico, porém, o projeto também precisou ser reajustado mantendo comunicação com os pais via internet, pelo celular. Considerando a questão sanitária, o acervo de livros da escola foi disponibilizado da seguinte forma: em um dia na semana (segunda-feira), ocorre a troca de livros para os pais na escola. Segundo a professora coordenadora, com isso há não só a valorização da leitura para formação do leitor, mas também o exercício de ser responsável por algo público. E explica a nova configuração do projeto (informação verbal): 
Com a educação remota, os pais apoiam no processo de mediação da leitura, como pontes.

A criança interage com o mundo literário, gibis, contos, fábulas, enfim, acervo com diversos gêneros literários.

Os pais se destacam em duas frentes: primeiro os pais escolhem e, também, levam para a escola o desejo de leitura dos filhos.

Os pais sentem a importância de incentivar seus filhos a ler, encaminham vídeos e fotos de forma espontânea, há registro desse impacto. (Fala da Prof. a Jacqueline Machado apud BARROS 2020).

Essa mediação dos pais harmoniza-se com o que diz Rubem Alves:

Toda a aprendizagem começa com um pedido. Se não houver o pedido, a aprendizagem não acontece. Há aquele velho ditado: É fácil levar a égua até ao meio do ribeirão. O difícil é convencer a égua a beber. Traduzido pela Adélia Prado: Não quero faca nem queijo. Quero é fome. Metáfora para o professor.

(...) E acontecerá com a leitura o mesmo que acontece com a música: depois de termos sido tocados pela sua beleza, é impossível esquecer. A leitura é uma droga perigosa: vicia... Se os jovens não gostam de ler, a culpa não é só deles.

Acho que as escolas só terão realizado a sua missão se forem capazes de desenvolver nos alunos o prazer da leitura. O prazer da leitura é o pressuposto de tudo o mais... (ALVES, Rubem, 2004)

O desenvolvimento da leitura dos clássicos acaba, então, por contribuir muito para a formação do leitor literário. Cosson, ao abordar a seleção de textos para o processo de letramento literário, ratifica a importância desses textos na formação do leitor, afirmando:

Têm razão os que afirmam que não se pode pensar em letramento literário abandonando-se o cânone, pois este traz preconceitos, sim, mas também guarda parte de nossa identidade cultural e não há maneira de se atingir a maturidade do leitor sem dialogar com essa herança, seja para recusá-la, seja para reformá-la seja para ampliá-la. (COSSON, 2010, p. 33-34) 
Por outro lado, Marisa Lajolo diz que os professores têm a obrigação de permitir que o aluno exerça uma certa escolha naquilo que vai ler. Ribeiro (2012, p.01) também concorda quando diz que:

As leituras tidas como despretensiosas formam escritores versáteis e com múltiplas competências linguísticas, tendo em vista a noção de competência linguística de Chomsky que é a capacidade inata que o indivíduo tem de produzir, compreender e de reconhecer a estrutura de todas as frases de sua língua.

Por isso, a professora Jacqueline destaca que (informação verbal): "relatos que chegam pelos pais de que "meu filho abraçou o livro e não queria devolver", mostram o quanto Projetos como esse são um alento em momento de Pandemia." Diante disso, Letramento Literário pode ser definido, em linhas gerais, como um conjunto de práticas e eventos sociais que envolvem a interação leitor e escritor, por meio da leitura de textos canônicos ou não (COSSON, 2009).

$\mathrm{Na}$ prática pedagógica, conforme Cosson (2014) o letramento literário pode ser efetivado de várias maneiras, mas há quatro características fundamentais: $1^{\circ}$ é preciso contato direto do leitor com a obra, é preciso aluno interagir; $2^{\circ}$ espaço compartilhado de leituras e respeito pelo interesse e grau de dificuldade; $3^{\circ}$ ampliar o repertório, reconhecer além de textos escritos, outros tantos suportes e meios e $4^{\circ}$ atividades sistematizadas e contínuas.

O supracitado autor propõe, pelo menos, duas estratégias metodológicas fundamentadas no modelo autônomo de ensino de literatura: as Sequências Básica (Motivação, Introdução, Leitura e Interpretação) e Expandida:

O uso da sequência expandida do letramento literário tem como centro a formação de um leitor cuja competência ultrapasse a mera decodificação dos textos, de um leitor que se aproprie de forma autônoma das obras e do próprio processo da leitura, de um leitor literário (COSSON, 2014, p. 120)

Diante do exposto, a proposta de Cosson pode ajudar muito o professor para favorecer o letramento literário no contexto atual. 


\section{CONSIDERAÇÕES FINAIS}

Este trabalho iniciou com o pensamento de Fernando Sabino especialmente porque nesse momento de Pandemia, em que a escola precisou amparar os alunos remotamente para promover o letramento literário, é necessário que o professor se reinvente e recomponha didaticamente e literariamente para efetivar tal propósito, pois quanto mais se usa a literatura como pretexto, por exemplo, para resumos e análises gramaticais, mais os alunos aprendem a odiar a literatura.

O relato dos projetos enveredou por reflexões acerca do esforço das professoras, ante a Pandemia, para favorecer a competência leitora dos alunos, em um processo educativo, utilizando diferentes estratégias de letramento literário: cordel, contos, curtas-metragens, em ambientes virtuais; e clássicos infantis, com registro em vídeo e mensagens de celular, o que corrobora para a ideia de que o professor não tem apenas um caminho para chegar ao aluno.

A partir dessas considerações, entende-se que a tecnologia pode ser aliada e não concorrente. Se, por um lado, traz o imediatismo, de outro vem possibilitando o acesso às obras, criando novas formas de comunicação e envolvimento entre professores e alunos.

Uma constatação importante a ser feita é quanto à motivação para a leitura, a qual varia de indivíduo para indivíduo. A cada idade, uma leitura. Criar maneiras de aproximação, mesmo que não sejam físicas, mas que proporcionem a valorização da literatura - indispensável ao crescimento intelectual do indivíduo e desenvolvimento da sociedade.

Esta pesquisa representa uma mostra de como os ambientes virtuais de aprendizagem podem ser importantes recursos para auxiliar na criação do universo literário, para conectar, interagir e registrar o impacto provocado pela leitura, não como algo imposto, mas cultivado dia a dia, mesmo em dias tão inconstantes.

\section{REFERÊNCIAS}


A leitura e o ensino da literatura. São Paulo: Contexto, 1988.

ALVES, R. O prazer da leitura. 2015. Disponível em: http://tatiana alfabetizacao.blogspot.com/2015/03/o-prazer-da-leitura-rubem-alves.html. Acesso em:

BARROS, F. A. de B. Letramento Literário em Tempos de Pandemia. Feira de Santana-BA. Publicado pelo canal TV Olhos D'Água - TV Uefs, 29 jul. 2020. 1 vídeo (1h:29min). [Live]. Disponível em: https://www.youtube.com/watch?v=BIR_OirSG7c. Acesso em: 08/08/2020. Participação de Simônica Neves, Kátia Bispo Brandão Santos e Eliene Ramos da Silva.

BRANDÃO, H.; MICHELITTI, G. (Coord.). Aprender e ensinar com textos didáticos e paradidáticos. 3 vol. $2^{\text {a }}$ ed. São Paulo: Cortez, 1997.

COSSON, R. Letramento Literário: teoria e prática. 2. ed. São Paulo: Contexto, 2014.

. Cultivando Leitores e Marisa Lajolo. Vídeo para Educadores FTD. Youtube, 25 out. 2018.2 Disponível em: https://www.youtube.com/watch?v=PA561_Pzau0. Acesso em: 20/06/2020.

FREIRE, P. A importância do ato de ler: em três artigos que se completam. 23. ed. São Paulo: Autores Associados, Cortez, 1989.

LAJOLO, M. O Que é Literatura. São Paulo, Ed. Brasiliense, 17ª ed. 1995. . Letramento literário: teoria e prática. São Paulo: Contexto, 2009. . Letramentos múltiplos, escola e inclusão social. São Paulo: Parábola Editorial, 2009.

MACHADO, J. Projeto incentiva leitura para crianças na pandemia. Entrevista concedida a André Bida. Ponta Grossa-PR. Publicado no Portal aRede.info, 29 jul. 
2020.

vídeo

(14min).

Disponível

em: https://www.youtube.com/watch?v=CN7Ex3K8JzM. Acesso em: 22/08/2020.

RIBEIRO, R. Promovendo o letramento literário no ensino médio (Promoting the literary literacy on high schoo). Universidade Federal de Brasília. 2012 Disponível em: https://bdm.unb.br/bitstream/10483/5441/1/2012_RicardoRibeiro.pdf. Acesso em:

ROJO, R. (Org.). Escola conectada: os multiletramentos e as TICS. São Paulo: Parábola, 2013.

SANTOS, C. J. de M. A literatura popular na sala de aula: uma proposta para o ensino de literatura literária. 2016. 127f. Dissertação (Mestrado Profissional em Letras em Rede Nacional - PROFLETRAS). Universidade Federal do Rio Grande do Norte, Currais Novos, 2016.

SEGABINAZI, D. M. (orgs). Língua literatura e ensino concepções diálogos e convergências. João Pessoa: Editora da UFPB, 2015.

Enviado: Novembro, 2020.

Aprovado: Dezembro, 2020. 